\title{
O triunfo e a dor da beleza: comparando as estéticas recursiva, contrapontística e celular do ser $^{1}$
}

\author{
George Mentore \\ Departamento de Antropologia - Universidade da Virgínia
}

\begin{abstract}
RESUMO: O principal argumento desenvolvido neste ensaio é o de que, para os Waiwai, o privilégio conferido à visibilidade lateral sugere idéias sobre um indivíduo fractal, associado ao poder recursivo, enquanto, para as sociedades do litoral da Guiana e dos Estados Unidos, o privilégio conferido à visibilidade axial sugere concepções sobre um indivíduo autônomo, associado a relações de poder contrapontísticas e celulares, respectivamente. Será argumentado que, ao contrário da situação dos Waiwai, de acordo com o objetivo de atingir maior eficiência no funcionamento de suas relações políticas com os cidadãos, o desejo do Estado moderno, expresso por meio do uso privilegiado da visibilidade axial, reduz a importância das relações laterais e produz indivíduos categorialmente isolados e solitários.
\end{abstract}

PALAVRAS-CHAVE: fractalidade, visibilidade, individualidade, conhecimento, verdade, poder.

\section{Introdução}

Munida da intimidade de experiência de campo e da crença no efeito completo dessa experiência em suas idéias, Joanna Overing tem praticado, como um princípio corporificado de sua pesquisa e ensino, um tipo 
delicado de cirurgia em muitos dos paradigmas ocidentais estabelecidos que estão calcificados na antropologia atual. $\mathrm{O}$ valor de seu trabalho, para mim, reside nas firmes tentativas de remover paradigmas rígidos que obstruem um entendimento claro e profundo do "conhecimento indígena”. O corte clínico resultante de suas idéias nos torna capazes de chegarmos mais perto das artérias das relaçôes humanas diferentes. Esse corte, por exemplo, nos deixou mais próximos do caráter e da qualidade de relações que existem em sociedades que privilegiam a emoção e a moralidade, em detrimento da racionalidade e das doutrinais legais do direito. Creio que tamanha conquista resulta de uma absoluta concentração durante os delicados procedimentos requeridos para atingir um controle adequado da assemblage cultural de conhecimento: um fenômeno claramente sujeito às fraquezas da ingenuidade humana. Assim, quando voltado ao estudo dos modos ameríndios de conhecer, o sólido credo de Overing continua sendo a própria impossibilidade de algum conhecimento existente sobre o mundo que também não proclame sua vida no mundo com algum tipo de viés moral. Há algum tempo, eu entendi que as séries de geminações entre moralidade e emoção, racionalidade e sistema legal são exatamente do mesmo tipo daquelas entre crença e certeza, poder e verdade. É com esses tipos específicos de concepçôes de minha professora que, aqui, eu me volto cuidadosamente a uma análise crítica comparativa entre formas de conhecimento ameríndias, antilhanas e norte-americanas sobre a existência social. Minha tentativa será um esforço emulativo de seguir minha professora na delicada cirurgia em teorias calcificadas. 


\section{A dor da beleza}

Ele inspirou. Prendeu bem a respiração. Um sentimento de pânico percorreu o seu corpo de cima a baixo. Foi deliberado. Ele quis imprimir em seu discurso, bem como em sua postura, o sentimento de um colapso paralisante. Haveria melhor maneira de emprestar a sua fala o clima de mau presságio? Towatowa lutou para contar com velhas palavras esta nova história sobre estranhos acontecimentos no outro lado da floresta:

"O povo do peixe-sol está se matando [ele explicou com uma expiração].

Estão se matando e matando suas criancinhas.

Muitos deles, muitos, muitos, deles.

Os urubus escureceram o céu.

Eles logo estarão embriagados de carne, de carne humana apodrecida.

A Terra irá se contorcer com tantos vermes.

É iminente. A beleza da aldeia terá desaparecido e a feiúra do que é ruim alardeará sua vitória.”

Enquanto Towatowa prosseguia, a multidão contemplava aturdida as palavras e imagens que recebiam. Muitos dias depois, os Waiwai da aldeia Shepariymo ficaram curiosos e intrigados. Nunca haviam pensado que esse tipo de morte poderia ocorrer no mundo.

Enquanto as notícias sobre o número crescente de mortos entre os membros do culto do Templo dos Povos em Jonestown circulavam na aldeia, observei especialmente como os Waiwai interpretavam e onde, em seu modelo intelectual, colocavam o conhecimento desses acontecimentos. $\mathrm{O}$ que apreendi foi que as sombrias forças xamânicas em ação deveriam estar influenciando ou atraindo o ekatï (vitalidade espiritual) de cada um dos templários. Só o trabalho de um sombrio desígnio xamânico pode extrair, de cada corpo vivo, essa vitalidade, que mantém a 
vida, e impedir que ela retorne ao seu hospedeiro humano. Como pode uma comunidade com tantas pessoas ser tão terrivelmente não compelida pela boa vontade a ponto de permitir que o desígnio da imortalidade causasse tanta destruição? Essa, creio, foi a pergunta insistente por trás do olhar de perplexidade em cada rosto. Acumular essa quantidade de má vontade contra tantas pessoas ao mesmo tempo e no mesmo local parecia, para os Waiwai, ser a coisa mais chocante que pudessem conceber e, de fato, a própria dor pela derrota da beleza. Para eles, só poderia haver um modo de viver, isto é, no esplendor da moralidade do parentesco, cujo principal objetivo é manter essa violência represada.

\section{Um instrumento heurístico}

Meu interesse antropológico nas experiências vividas categorizadas, consideradas agradáveis à sensibilidade indígena, tem origem em uma etnografia interpretativa sobre um código de conduta ameríndio. No principal caso em discussão - os Waiwai do sul da Guiana -, uma beleza conhecida anima os modos de vida bons e adequados - uma estética da moralidade habita suas vidas cotidianas. Útil às minhas preocupações antropológicas em identificar e descrever esse intangível, a vivacidade da estética da moralidade waiwai se apresenta expressamente movendose além das relações humanas sociais e no plano dos objetos inanimados. Primeiro, eu segui a prova do conhecimento teórico e da experiência da estética dos Waiwai, baseado na sensação comum do prazer proporcionado pela beleza reconhecida e apreciada de um objeto construído. Nesse momento inspirado, eu me permiti contemplar os padrões repetidos, tramados na cesta que chamam pakara. A trama sobreposta da palha não serve apenas como metáfora das relações propriamente humanas, a forma telescópica de seu plano ecoa uma filosofia do 
Revista de Antropologia, São Paulo, USP, 2006, v. 49 no 1.

ser social mais ampla, que demonstra um desejo informado de coibir a má vontade em relação aos outros.

Num esforço de melhor entender e apresentar essa estética, eu irei comparar e contrastar o privilégio tradicional que eles conferem a "uma boa vida com os outros" com o Ocidente moderno, que se pode presumir com base nos direitos naturais de um indivíduo idealmente mantido e protegido por meio de relações com o poder estatal centralizado. Primeiro, deixe-me compartilhar com vocês o instrumento heurístico que apliquei ao empreender esta análise.

Aqui, trabalho em termos da antropologia clássica, que entende que os espaços sociais são capazes de produzir relaçóes pessoais. No caso dos Waiwai, essas relações são primariamente de parentesco. Argumentarei que a visibilidade e o agenciamento desses espaços sociais de parentesco figuram de modo proeminente como o meio de vivenciar, conhecer e confirmar a boa vida com os outros. Considerando a propensão desses espaços sociais serem o meio de negociar relaçôes humanas, dois tipos de visibilidade serão identificados: lateral e axial. ${ }^{2}$ Como metáforas de relaçôes espaciais pregnantes de idéias de poder, as visibilidades lateral e axial servirão como conceitos gerais da análise comparativa.

Os dois tipos se relacionam de maneira multifuncional e covalente para produzir, para cada Waiwai, o feito de ser uma pessoa completa. Quando utilizados, contudo, em sociedades ocidentais ou ocidentalizadas, é o predomínio da visibilidade axial sobre a lateral que mantém o desejo de completude constante, embora constantemente fora de alcance. Nessa postura moderna dominante da prisão panóptica, em que a relação entre a torre de vigia central da guarda e a cela do prisioneiro opera como a forma utópica de poder, a visibilidade axial atravessa todos os domínios institucionais. A forma panóptica nega visibilidade lateral ao prisioneiro isolado. Por conseguinte, como forma estratégica de poder e metáfora principal para a situação moderna de corpos/células autô- 
Mentore, G. O triunfo E a dor da Beleza...

nomos, o Panopticon também nega relações compartilháveis entre prisioneiros/subjetividades em células/corpos contíguos (Foucault, 1978).

Conceitualmente determinadas por um princípio de fractalidade, entre os Waiwai, as visualidades lateral e axial permitem o preenchimento de uma almejada totalidade dos seres sociais. Dependente de um movimento ou processo de ação recursivo, a pessoa fractal aparece como indicativa de uma entidade social igualitária. Mesmo em sua expansão ou magnitude social, a pessoa fractal retém sua escala. Por exemplo, qualquer acréscimo de status social não significa uma mudança proporcional na qualidade da existência humana. Argumentarei, contudo, que a proeminência da visibilidade lateral sobre a axial, entre os Waiwai, estimula os efeitos societais distintivos de sua coletividade moral e esteticamente agradável. Enquanto criado pela primazia da visibilidade lateral, esse efeito agradável sobre a sensibilidade tem a capacidade de ampliar a habilidade de criar tal experiência, operando ativamente contra qualquer noção de individualidade isolada. Em última instância, o que isso significa no pensamento waiwai é que singularidade e solidão não podem ser apreendidas e discernidas como maneiras virtuosas ou éticas de viver e, de fato, são consideradas ruins e feias por suas sensibilidades.

É claro que muitos outros elementos contrastivos existem entre a modernidade ocidental e o material waiwai para que uma análise cogente seja persuasiva. Para ganhar uma força relativamente moderada no jogo entre a construção da emoção e do pensamento, da moralidade e dos direitos, do sentido e da racionalidade, contudo, iremos nos concentrar em uma comparação entre as maneiras pelas quais cada um imagina e lida com o individual. São as relações contextuais entre conceitos sobre o que constitui o indivíduo e a significativa nostalgia ou desejo de realização desse ser que levam à base de minha análise. Quanto ao instrumento heurístico, a análise comparativa considera os efeitos sobre os indivíduos de uma sociedade que privilegia um tipo de visibilidade so- 
bre o outro. A tarefa se torna um pouco mais difícil para mim por ter de comparar o material waiwai não apenas com as noções de indivíduo moderno que emanam da cultura norte-americana, mas também com aquelas existentes na cultura do litoral da Guiana - uma sociedade póscolonial ex-britânica.

\section{O triunfo da beleza}

Os Waiwai, é possível afirmar, idealizam as relações sociais como se elas manifestassem um padrão entretecido, que se revela como palhas individuais, alternadamente por cima e por baixo umas das outras, como responsabilidades humanas conhecidas. $\mathrm{O}$ padrão vincula woyesï, a replicação de um ato em uma seqüência que tende a uma assemblage, em outras palavras, um padrão tramado assimila em si mesmo cada uma de suas tramas anteriores. Quando funcionam como o efeito geral de uma firme trama compacta de relações, essas "palhas de responsabilidades" constituem a vida substantiva e plena de um indivíduo como pessoa social. Ao mesmo tempo e no mesmo espaço do corpo social, as palhas da responsabilidade se reunem como o próprio agregado social, bem como a voracidade das subjetividades individuais.

Aqui no conhecimento antropológico conceitual da sociedade waiwai - como eles poderiam manifestá-la como ewto e ser interpretado pela antropologia como "aldeia" -, nenhuma distinção deve ser feita entre sociedade e indivíduo. A palavra waiwai para indivíduo humano é toto. Em ewtoto: significando tanto "o lugar onde as pessoas vivem" como "as pessoas que vivem nesse lugar", as duas palavras são unidas para formar uma só. Observar isso é a conclusão antropológica precisa sugerida pela "pessoa fractal", na qual "nunca se trata de uma unidade em relação com um agregado, ou de um agregado em relação com uma unidade, 
Mentore, G. O triunfo E a dor da Beleza...

mas sempre como uma entidade com relações tácitas" (Wagner, 1991, p. 163).

Segundo o modelo waiwai da pessoa completa, èewyarono, a vitalidade da substância espiritual (ekatì) deve primeiro habitar e dar vida ao corpo. Ao fornecer calor, movimento, emoção, pensamento e consciência ao indivíduo, a vitalidade espiritual torna-se dispersa e abrigada em vários locais dentro e através do corpo. A vitalidade espiritual dos olhos (ewrikati) pode ser observada quando a diminuta imagem de si mesmo pode ser vista refletida nos olhos de outra pessoa. A vitalidade espiritual do peito (ewankati) está localizada no centro cavernoso do plexo solar. Mesmo o próprio calor do corpo vivo é prova das substâncias espirituais necessárias à manutenção de uma vida ativa. Além dessas subjetividades diferenciais (possíveis graças às noções waiwai do corpo como possuidor de diferentes regiōes ou partes que oferecem abrigo ou "lugar" a tais subjetividades), a substantividade social do corpo deve estar presente e ativada pela èewyarono para ser integralmente no mundo como um comentário apropriado sobre o mundo. ${ }^{3}$

As relações recíprocas de responsabilidade por outros considerados o-yepamrï (meu-parente) condensam a identidade social de um èewyarono. Uma pessoa dessas é tão completa em relações yepamrï, ela entende a si mesma independente de necessidade ou auxílio externos, que tudo pode ser conquistado e alcançado no interior do tipo de completude implícita em ser èewyarono. Subtrair ou adicionar infinitamente a essa completude não pode, contudo, alterar de modo proporcional um èewyarono. Exatamente como a palha individual de um cesto sendo tramado, o caráter fractal da personalidade èewyarono sempre junta seqüencialmente na direção ou além de um suplemento ou uma assimilação de completude. No exato momento ou no exato ambiente de ser possivelmente sem parentes (possivelmente adicionando ao infinito para se tornar um ser supremo), èewyarono substantiva e recursivamente con- 
Revista de Antropologia, São Paulo, USP, 2006, v. 49 no 1.

sidera parentes proporcionais. Por exemplo, na sociedade waiwai, mesmo um convidado/visitante (pawana) desconhecido no meio da comunidade imediatamente torna-se e, de fato, conceitualmente sempre foi wošin (afim) e epeka (consangüíneo). Todos aqueles que instantaneamente se referem ao visitante como wošin - como é o costume - terão naqueles que vivem na comunidade que os chamem wošin, chamando o visitante seu epeka. De maneira anedótica, de acordo com essa compreensão da sociedade, a primeira pergunta a ser feita a um visitante não é "onde está seu passaporte?", mas “onde estão seus parentes?”.

O movimento de fractalidade e completude operativo em èewyarono talvez tenha seu corolário mais óbvio no sistema de contagem waiwai de šim-šim ou ukoknon macho. Šim-šim de fato refere-se mais deliberadamente ao cordão com nós utilizado para contar os dias que faltam para eventos cerimoniais. $\mathrm{O}$ conceito de uma unidade recorrente de um pode ser inferida da repetição onomatopaica da palavra šim e de cada nó feito ou desfeito no cordão. As duas inferências implicam o sol e seu movimento através do céu "amarrando" ou completando um dia. ${ }^{4}$ Notar especialmente a palavra mão, kamorï, que é construída a partir da palavra sol, kamo. No entanto, é em ukoknon macho que a idéia da contagem recursiva está melhor expressa. De modo bastante interessante, eles chamam o relativamente recém-introduzido calendário ocidental nuni ukoknon, e mapa chamam de rowo ukoknon. Aqui, a inferência parece ser que, como a contagem, a câmara, o calendário e o mapa repetem holisticamente os objetos que chamam sua atenção. Em outras palavras, eles tanto fazem o trabalho de assemblage: eles reúnem a imagem do sujeito/objeto na fotografia, o ressurgimento da lua e a superfície da terra, respectivamente. Essa montagem requer o movimento seqüencial de completude para proporcionar, em sua ação, a fractalidade que retorna à completude mais uma vez. Assim, o princípio mesmo de recursividade pode ser apreendido nos termos waiwai de contagem. 
Mentore, G. O triunfo e a dor da beleza...

Eles de fato possuem um sistema de contagem recursivo que fornece quatro números básicos: èewñe (1), asakï (2), osorowau (3) e thathoyere (4). Esse, todavia, é um sistema em que os dígitos contados assimilam os números finais alcançados. Portanto, adicionar outro dígito a thathoyere daria èewñe-kamorï (5 ou, literalmente, "uma mão"). Continuando da mesma maneira, a seqüência se repete, mas como èewñešahara-kamorï (6 ou "um e uma mão"), asakï-šahara-kamorï (7 ou "dois e uma mão"), osorowau-šahara-kamorï (8 ou "três e uma mão"), thathoyere-šahara-kamorï (9 ou "quatro e uma mão") e hanoro-kamorï (10 ou "outra mão"). Às vezes, no lugar de hanoro-kamorï, eles podem dizer asatho-kamorú, que pode ser literalmente traduzido como "um par de mãos" ou "mão duplicada". Embora iraèon-hïrame-kitarï possa ser traduzido literalmente como "um pé separado de seu par", tem o significado principal de "duas mãos e um pé", em outras palavras, a montagem de 15. Hanoro-kïtarï, embora traduzido por "outro pé", na verdade significa a montagem de 20. Essa seqüência de contagem nos dedos dos pés e das mãos, nas mãos e nos pés, que torna evidente o sistema numérico recursivo waiwai, também revela, no constante completar do todo, um indivíduo humano singular: um toto.

$\mathrm{O}$ agregado reunido do indivíduo sempre implica integralmente suas entidades fractais e as entidades fractais que seus agregados reúnem. A escala ou proporção permanece a mesma; não importa onde, quem ou quando, a escala humana conceitual do indivíduo não se altera. Até a perfectibilidade do èewyarono se manifesta como uma instância numa proporcionalidade muito humana. Qualquer incremento no status social tem de manter sua escala; é proporcionalmente exato e holístico em sua multidimensionalidade. Qualquer instância de tal grandeur retorna ao que lhe era precedente a fim de manter sua escala humana: qualquer aumento de status social, portanto, não altera as proporções do indivíduo ou da sociedade. Em vitalidade espiritual e em ser social, a soma 
Revista de Antropologia, São Paulo, USP, 2006, v. 49 no 1.

fractal e total do indivíduo, enquanto pessoa, retém as características definidoras de uma escala bastante humana, mesmo em sua magnitude.

Os Waiwai aplicam o mesmo critério estético a todas as coisas bonitas bem como à fabricação de seres sociais apropriados. Os pontos de assemblage para a cultura material, a humanidade e a socialidade são para eles deliberadamente de caráter recursivo e implicam, eu afirmaria, o mesmo esquema conceitual de um contínuo entre a fractalidade e uma totalidade agregada.

Considere a categoria de o-yepamrï, meu parente, como a escala de contribuição para a assemblage adequada da pessoa completa, èewyarono; ela sempre exemplifica o fato de erowaray - a similaridade na aparência das coisas. No caso de parentes, ela exemplifica as semelhanças entre indivíduos do mesmo ventre e, por implicação, da mesma aldeia. No entanto, é woyesï, como a reunião seqüencial ativa de parentes, que de fato permite que as semelhanças sejam observadas e, com efeito, sejam a instância para o comentário sobre as palhas da responsabilidade social. Eenporin, a beleza, pode ser apreciada como essa assemblage de parentes. É a totalidade ou unicidade produzida pela recursividade da reunião que mantém a estética. As semelhanças entre parentes sugerem um equilíbrio: uma espécie de harmonia agradável à sensibilidade waiwai. $\mathrm{O}$ mesmo efeito pode ser produzido em pontos de assemblage diferentes daquele dos parentes, por exemplo, de cestos, canoas e casas, mesmo na abóbada do universo. Ainda assim, a produção de tal prazer na beleza do completo, da unicidade, necessita do impulso gerador da diferença. Em outras palavras, semelhanças entre parentes já implicam uma fractalidade integral.

Para voltar agora a èewyarono como um exemplo de status social ampliado que, apesar disso, retém sua escala humana e suas proporções inalteradas. Creio que possamos determinar o fato, aparentado - que define a magnitude de èewyarono - reúne como a fractalidade da com- 
Mentore, G. O triunfo e a dor da beleza...

pletude. Quando apropriadamente colocado como as palhas da responsabilidade, essa agregação por parentesco fornece o prefixo èew em èew$n$ (um) ao prefixo èew em èew-yarono: yarono, o acordo, yaro, ou verdade do assunto, nesse caso, a óbvia beleza expansiva da totalidade reunida por parentesco em èewyarono. A seqüência segue o mesmo padrão do começo ao fim. Por exemplo, no caso particular de um èewyarono ter parentes na categoria de karipamšam - termo para homens jovens não casados -, o prefixo kari deriva diretamente da palavra kari-tu, que significa ser ou sentir-se forte. $\mathrm{O}$ radical de pam tem seu equivalente no radical da palavra ye-pam-rï, parente. É como se a montagem para o conceito de parente viesse da fractalidade da força dos moços. E, no entanto, a força da masculinidade juvenil tem sua fonte, apesar de tudo, nas categorias preexistentes da vida adulta.

$\mathrm{O}$ crescimento social dos jovens, moços e moças rumo à vida adulta retém uma escala relativa. Karipamšam e emasï (mulheres jovens não casadas) complementam-se mutuamente e, dessa maneira, dão uns aos outros o potencial relacional de se tornarem porintomo (homem adulto) e anaèwan (mulher adulta), respectivamente. O casamento e a paternidade transformam karipamšam e emasï em porintomo e anaèwan. Como a força dos homens jovens deriva de seus pais, recursivamente, ela constitui o próprio suplemento necessário para formular a individualidade do novo jovem homem adulto. $\mathrm{O}$ mesmo pode ser dito em relação à mulher jovem e de seu crescimento social em mulher adulta. As palhas da responsabilidade integralmente implicadas em cada indivíduo dão forma enquanto pessoas proporcionalmente completas. No sistema de parentesco waiwai, os termos na segunda geração acima e abaixo de ego designam todos como parentes. Ou seja, por causa da completude precedente de porintomo e anaèwan, pessoas mais velhas na forma, de acordo com o gênero, de pocha (velho) e chacha (velha) tornam-se ao mesmo tempo avô e avó de qualquer um na mesma geração de ego. De maneira 
Revista de Antropologia, São Paulo, USP, 2006, v. 49 no 1.

similar, mas sem a diferença de gênero, todos na segunda geração abaixo de ego tornam-se $o$-parï (neto/neta) para aqueles na geração de ego. Creio, no entanto, que é nas categorias particulares de ewto mïtwim ou ewto yusom (literalmente "líder da aldeia") que podemos ver melhor a consistência do modelo conceitual para o sistema de ser recursivo dos Waiwai e sua tendência a produzir um triunfo de beleza, mesmo quando ocorre um aumento proporcional de status ou poder.

Hoje os Waiwai utilizam a palavra kayaritomo para líder da aldeia com muito mais freqüência do que ewto mïtwim ou ewto yusom. Obtive essa informação de uma fonte com autoridade; os missionários introduziram essa palavra durante a década de 1950, quando estavam realizando um trabalho de evangelização e traduzindo a Bíblia para waiwai. Parece que combinaram a palavra karitu (forte) e into (radical de grande) para captar as concepções waiwai do poder abarcante e singular envolvido na liderança política. Dada sua perspectiva norte-americana particular sobre os indivíduos e os sistemas políticos, a intenção dos missionários texanos deve ter sido interpretar a liderança waiwai em termos de um poder axial acumulado e possuído no centro. $\mathrm{O}$ que deve lhes ter parecido os "chefes" waiwai - grandes homens cujo aumento do status social parece ter conferido a autoridade para comandar e ser obedecido - permitiu aos missionários usurparem a antiga palavra em nome da nova. Teria sido muito difícil para eles não verem o impulso lateral das palhas de responsabilidade waiwai?

Apesar de kayaritomo ter substituído os antigos termos para líder da aldeia, a natureza da liderança inquestionavelmente permanece de acordo com o sentido tradicional. Os líderes waiwai absorvem as forças concêntricas laterais da sociedade, permitindo que eles mesmos estejam sujeitos às tarefas que realizam e que desejam que outros participem. A obediência não se origina de nenhum comando, punição ou possível punição diretos feitos por indivíduos ou grupos, mas antes do conheci- 
Mentore, G. O triunfo E a dor da Beleza...

mento de uma relação integral preexistente entre o eu e o outro que delimita a distinção entre os dois. Quando alguém se convence a fazer certa coisa, ele implica outros - que já são parte de sua identidade fractal - que também farão isso como uma repercussão integral de si mesmo. Assim, qualquer acúmulo ou aumento de prestígio, privilégio ou autoridade derivados de realizaçóes de um indivíduo importa uma magnitude similar de fortalecimento de outros. Em outras palavras, o exercício de poder produz o seu próprio impacto de subordinação em quem o exerce, bem como naqueles sobre os quais é exercido. Embora de um estreito ponto de vista, a hierarquia pode claramente ser observada na crescente elevação de cada círculo dentro do círculo; quando conhecido e vivenciado como fractal, o poder concêntrico lateral reduz e anula a impressão genérica de graduação. Aqui o sistema recursivo de poder produz uma estética política, nunca reduzindo o indivíduo a uma entidade isolada vulnerável aos efeitos negativos da dominação.

O conforto e o consolo adquiridos por ser uma pessoa fractal entre os Waiwai é o triunfo da beleza. A autonomia individual não pode ser contemplada. Se pudesse, seria como algo distante e informe no horizonte de experiência: triste e feio. De fato, uma autonomia que leve à solidão seria o resultado óbvio de tal ser, mas, na teoria waiwai, um ser totalmente fora de questão. Em seus modos de conhecimento, autonomia e solidão nem sequer podem ser postas como possibilidades, muito menos como uma dúvida. Em vez de impormos nossas próprias teorias sobre o ser e o tempo, talvez devêssemos tentar aceitar o óbvio: seus pressupostos e meios de conhecimento existem em diferentes contextos históricos e culturais. Em seu sistema de conhecimento, a busca de ser completo na perfectibilidade de uma individualidade autônoma não tem por que ser desejável. Aqui, a busca em objetivar a singularidade de uma vida individual, como uma experiência no tempo cronológico, não pode começar a ter influência. Por essa razão, o tempo disciplinar não 
pode ser utilizado como uma técnica coercitiva sobre o corpo. Mensurar, protrair, documentar e competir contra o tempo, para reivindicar uma vitória completa sobre a vida ou conduzir a vida sob atenta observação e controle, não parecem ter relevância para os Waiwai. A beleza de uma vida intensa existe e não pode ser negada a nenhum indivíduo que chegue a seu mundo social preexistente. Parentes reunidos existem em sociedade, por isso você já existe. O sistema recursivo dos Waiwai de se tornar uma pessoa social distribui o esplendor da vida, não como momentos extraídos de uma ausência, mas como um reconhecimento simultâneo da presença preexistente.

\section{Autoridade contrapontual}

"Destroçar”, "Recarregar”, "Bin Laden”: palavras sobre veículos particulares, hoje elas designam propriedades estimadas e proclamam o poder de possuir de seus donos, exercido em um agressivo estilo masculino. Texto virulento e vibrante disposto na frente e nos lados de táxis, microônibus e carroças puxadas por burros para capturar sua atenção enquanto aceleram pelas ruas agitadas de Georgetown - a capital da Guiana. Essa é a paisagem litorânea urbana dos soldados que estavam estacionados em Kanashen quando os Waiwai estavam recebendo as notícias sobre a morte dos templários. Aqui, oralidade e textualidade têm uma longa e contínua relação: as palavras falada e escrita foram empunhadas por antigos guerreiros no teatro do conflito humano desde o momento em que o colonialismo pôs os pés no Novo Mundo. Atraído para a muralha da voz, o texto europeu ainda continua, na Guiana atual, a ser hipnotizado pelo poder de estilos discursivos contrapontísticos da África, Índia e China. Aqui, no delírio de sua arrogância, o texto com freqüência apresenta-se de modo confiante como o senhor e não como o escravo da voz. 
Mentore, G. O triunfo E a dor da Beleza...

O conceito de indivíduo nesse arranjo social, eu diria, pode ser apreendido por meio de uma compreensão da autoridade contrapontística da voz. (Devido à confusão histórica, lingüística, regional e teórica em torno do uso do termo creole, para mim a palavra "contrapontística" cumpre o trabalho de exprimir a idéia de "mistura", que o termo anterior exprime nos trabalhos acadêmicos atuais das Antilhas. Em tributo a um artigo pouco conhecido mas provocante de Karl Riesman (1974), chamado "Conversas contrapontísticas", eu também considero que o que ele evoca como fala em Antigua é um instrumento analítico útil para interpretar tanto a identidade guianense como a antilhana em geral.) Onde o apelo direto a uma platéia humana fornece o sentido mais importante e corroborativo da fala que fortalece o indivíduo, mais do que a escrita, domina completamente a cena social. Aqui, a visibilidade lateral para uma platéia reunida fornece o sentido primário da presença que realiza e conforta o indivíduo. Mesmo quando esse público pode ser considerado imaginário, por exemplo, quando um indivíduo falar consigo mesmo, um apelo a espectadores reunidos impulsiona o orador e supóe um interlocutor para a voz. Isso não é loucura. Trata-se antes de uma presença declarada em uma campanha cultural contínua para redimir o respeito humano individual.

Para aplicar esse tipo de teoria da performance à sociedade guianense, é preciso levar a sério o sentido de honra individual, primeiro tornado desejável, depois permanentemente mantido fora de alcance pelos mistérios perceptíveis da estima, cujas origens aparecem perdidas em uma história de escravidão, emancipação, servidão consentida e cobiça metropolitana européia (Abrahams, 1983; Patterson, 1982; Rodney, 1981; Wilson, 1973). Esse processamento do conceito de visibilidade lateral por meio da fala contrapontística afetuosamente envolve os supostos ideais negativos e de separação acerca da "impureza" e "fragmentação" instituídos em sociedades influenciadas pela cultura e história antilha- 
Revista de Antropologia, São Paulo, USP, 2006, v. 49 no 1.

nas. Talvez desconcertantes para nós, mas normal para a sociedade litorânea da Guiana, a autoridade contrapontística aclama os atributos positivos da mistura e da ambigüidade. Ao fazer isso, ela não apenas afasta do eu vulnerável a consciência cultural da vergonha como também recupera para o indivíduo um orgulho e uma dignidade na apropriação e exibição do impuro e fragmentário. Apesar de seu desejo avassalador de ser subjugado pela visibilidade axial dos ideais racionalistas europeus, até o Estado guianense teve de lidar com as realidades de seu próprio predomínio como um governo contrapontístico distinto. Provavelmente desconhecidos, talvez por isso mesmo, os atributos contrapontísticos distintivos de seu Estado são infundidos desde uma cidadania cujas vidas expressivas dependem de uma apresentação peremptória de um individualismo gregário.

Brilhantes, ruidosos, pungentes, ardentes, picantes, estes atributos da sociedade litorânea da Guiana confundem-se com o suave, ameno, claro, sereno e moderado para formar uma estética do ser: mais vivida do que pensada. Posta em um dramático palco de contradições, a consciência de ser Terceiro Mundo, de ainda ter de se "modernizar" e virar "Primeiro Mundo", a verdadeira realidade vivida desse ser, no momento em que é vivida como tal, não apenas é explicada como uma forma inferior de existência mas também como forma de existência nula. É como se, diante de seus olhos, a sociedade litorânea guianense deliberadamente se apoiasse em seu centro axial, a torre racionalista ocidental da modernidade, apenas para estabelecer um contraponto entre ela e as relações laterais, em uma exibição contrapontística de um sistema de autoridade alternativo. Juntos, o centro e a circunferência cancelam-se mutuamente na atuação da vida cotidiana. A segurança que a circunferência lateral fornece contra o centro requer a ação combinada de ambos, a supressão deste e o triunfo daquela, enquanto realiza semelhante triunfo como se não fora triunfo algum. ${ }^{5}$ 
Mentore, G. O triunfo E a dor da Beleza...

O esforço axial para conferir inferioridade não apenas a relações laterais mas também a qualquer identidade antilhana alternativa depende da negação da validade interpretativa da mimese. O mimético claramente amplia a representação. Ele permite, por exemplo, que o familiar seja reconhecido em cenas pouco familiares. Ele também, acriticamente contudo, permite ao copiado evitar a acusação de ser forjado: a cópia serve para dar ao original sua originalidade. Este último aspecto tem servido à transmissão do poder colonial (no momento em que, diz-se com freqüência, verdade auto-evidente em vez de coerção política, produziramse a experiência e o conhecimento do ser colonizado). A estrutura da mimese permitiu aos poderes coloniais - que consideram o mimético como uma forma inválida de ser - fazerem a reivindicação segura e evidente, por exemplo, que a cópia não tem credibilidade por si mesma. Quando o olhar atento colonial vê a cópia, em vez de ser vista como a repetição do progresso autêntico, real, verdadeiro e até natural ligado a forças inevitáveis do desenvolvimento, é vista como um índice de infantilidade, inocência e fraqueza. Por outro lado, o que aos incrédulos da autenticidade parecia ser o produto equivocado do mimético, os poderes coloniais interpretam como a óbvia abordagem racional do conhecimento e do ser. Por exemplo, em vez das palavras e crenças dos poderes coloniais, os colonizados vestem camisa e gravata, ouvem música clássica, estudam para se tornarem cultos e adotam sistemas parlamentares bipartidários porque eles nos copiam, dizem esses poderes, os colonizados fazem isso simplesmente porque é a coisa racional e apropriada a ser feita.

Poderes ocidentais e ocidentalizados preferem essa explicação porque ela desvia a atenção do fato de que seu suposto "original" é ele mesmo fabricado. As idéias ocidentais e ocidentalizadas sobre a identidade individual participam e produzem, embora neguem ostensivamente, o papel que representam na invenção e classificação da individualidade 
no original. Para essas idéias e esses indivíduos identificados por elas, resulta a sensação confiante do fortalecimento e de benefícios legítimos; ela resulta diretamente do interior de sociedades estabelecidas e determinadas por conhecimentos e verdades ocidentais. O caráter de um certo tipo de ordem racionalista infiltra-se. O caráter de um tipo de docilidade irônica também se torna evidente na produção e manutenção de uma ordem racionalista. Enquanto o policiamento da dor e a humilhação se sobressaem como um esforço para alcançar um maior sentido de valor moral, ele fica aquém da preocupação de monitorar os esforços necessários para estabelecer maior controle e obediência.

Permitam-me dar um breve exemplo da política estatal guianense: um caso do mimético, a influência do colonialismo e a persistência de valores modernos ocidentais para produzir instâncias e locais de visibilidade axial.

Impressa em letras pretas e vermelhas, em letreiros de Perspex branco, do lado de fora dos portóes de muitos ministérios em Georgetown, está a ordem:

Damas: não utilizar sandálias, bermudas, vestidos ou blusas com alças ou sem alças, bustiês ou tubinhos, camisetas com dizeres ou desenhos indecentes. Cavalheiros: não utilizar sandálias, shorts ou bermudas, calções, camiseta regata, colete, camiseta com dizeres ou desenhos indecentes. Vistam-se apropriadamente - poupem-se de qualquer constrangimento. Por ordem da direção.

Aqui, não tenho espaço ou interesse em expor de maneira aprofundada os sentidos relevantes que supostamente operam nos conceitos guianenses sobre o adorno corporal. Deveria ser tido como certo, no entanto, que uma lógica cultural particular funcione para estruturar o código de vestir que o Estado procura administrar. Aqui, estou menos 
Mentore, G. O triunfo e a dor da beleza...

interessado na lógica do poder axial de organizar conceitos de adornos corporais e mais na significativa preocupação do Estado com o seu poder de ordenar e ser obedecido vis-à-vis coisas como o adorno corporal.

Uma vez, eu tive de literalmente dar minha camisa a um homem que viajara mais de 80 quilômetros de uma comunidade litorânea rural para a cidade, para ter seu dente extraído por uma clínica odontológica administrada pelo Estado. O guarda uniformizado no portão da clínica impediu que ele entrasse porque sua camisa estava rasgada. Exemplos desse tipo de ansiedade do Estado pela falta de respeito por seu poder são muitos. Eles se tornam ainda mais incompreensíveis pelo fato de vários de seus agentes saberem muito bem as dificuldades envolvidas em viajar para a cidade de uma comunidade rural e a indignidade sentida por aqueles que têm de se curvar para receber ajuda do Estado. Ante a perspectiva de que a desejada, embora não retribuída, existência moderna e celular de seus cidadãos possa ser minada pelo aporte de fontes laterais, o Estado e sua vulnerabilidade colocam no centro aqueles na condição de se comportarem draconianamente. Os guianenses que agem sob a influência da cultura litorânea de fato possuem e instigam os mecanismos de um princípio e a estética de uma existência que encontram conforto no lateral, oposto às visíveis estratégicas axiais do ser. Essa alternativa, porém, ameaça a autoridade do Estado e mina sua confiança em dar ordens e receber obediência de seus cidadãos.

No meio do cruzamento mais movimentado e no dia de compras mais agitado da cidade, uma vez eu, com muitos outros, testemunhei uma briga entre dois homens. Eles estavam nus da cintura para cima. Ambos tinham os punhos cerrados e erguidos. Estavam em pose de pugilistas de uma gravura arcadista. $\mathrm{O}$ trânsito inteiro parou e o engarrafamento chegou a no mínimo quatro quadras. Uma multidão de pedestres dava voltas em torno dos protagonistas, impedindo que microônibus, carros, motos e veículos puxados por cavalos se movessem. 
Revista de Antropologia, São Paulo, USP, 2006, v. 49 No 1.

Os pugilistas se golpearam e a multidão rugiu. A multidão estava em júbilo. Os pugilistas estavam sérios. Os policiais à paisana, que normalmente estão no local para controlar o trânsito, estavam misturados à multidão. Ninguém pensava em apartar a briga. $\mathrm{Na}$ verdade, a opinião geral parecia ser a seguinte: um deles insultou o outro, e a necessidade de vingar ou defender a honra levou-os à briga. Nenhum dos presentes parecia incomodar-se com o fato de que a principal via de trânsito na capital estivesse interrompida por dois homens no dia mais agitado da semana.

Na sociedade litorânea da Guiana, por meio de diversos códigos informais de conduta pública, cada indivíduo intuitivamente sabia e sentia que tinha acesso imediato a uma justiça moral situada em um público. O direito de resposta provém de um sentimento aprendido de valor próprio, confirmado pela propriedade, evidente e expressiva, da voz. Parecia, ao menos para mim, que a mesma exigência de respeito pelo Estado existia nos cidadãos. O que o Estado busca por meio de textos, os cidadãos buscam mediante a voz. Ambos ativos na cultura guinanense para compensar ou manter a distância o "olhar de cima".

"Olhar de cima", ou o que é chamado em outras partes das Antilhas de "olhar cortante", foi definido como "uma tentativa deliberada e agressiva de privar ou reduzir a existência de outra pessoa" (Sanders, 1987, p. 135). No uso comum, "olhar alguém de cima" equivale a "humilhar ou desprezar alguém, arvorando-se alguma forma de superioridade" (ibid.). Externar desrespeito deliberadamente - para envergonhar alguém publicamente, reclamando para si um padrão moral mais elevado - é considerado um ato de suprema injustiça. Porque seu alvo são as inadequaçóes do indivíduo que é humilhado; "olhar de cima", enquanto uma técnica oblíqua de chamar atenção para a estima do indivíduo que humilha, é sempre considerado iníquo. Além das pretensōes de honra que a pessoa que "olha de cima" tem mas não merece, é injusto 
Mentore, G. O triunfo e a dor da beleza...

ou mesmo imoral construir a própria estima à custa de outra. Alguém que despreza tanto uma pessoa não seria dissuadido pela capacidade que ela tem de se defender da humilhação, fazer isso é negar que essa pessoa apenas fuja. Todo indivíduo possui a moral irredutível de uma honra que pode e deve ser defendida. Desrespeitar tal honra, "olhar de cima" para a honra de alguém, atacando-a deliberadamente, inflige um dano emocional ao indivíduo (e, eu talvez devesse acrescentar, à própria comunidade). É uma forma injusta de violência porque age desde o falso pressuposto de uma fraqueza moral da parte da vítima (e talvez até da parte da comunidade da vítima).

Quando os guianenses contrapontísticos defendem sua individualidade, ajudam a orquestrar e orquestram uma estética da socialidade, permitem que a justiça percebida como natural manifeste sua presença absoluta. Incorporar mais do que subjugar a contribuição de oponentes fornece uma moralidade inerente para ingressar na sociedade e exibir sua existência. Mesmo no teatro político, em que sabidamente as relações entre o Estado e os cidadãos são desiguais, o caráter do ingresso e da representação dessa moralidade só pode ser sugestivo de uma relativa equidade horizontal. Isso ocorre porque suas características dependem completamente das contribuições explícitas de outros. O guianense contrapontístico sempre busca de maneira agressiva envolver outros, trazêlos para o interior do contraponto e, ao fazer isso, dá um sentido lírico à existência moral. Cada contribuição é um acréscimo ao volume e à forma orquestrada da existência moral. Na sociedade litorânea, a autoridade contrapontística desnuda a mentira impregnada nas pretensões políticas modernas à democracia e ao "império da lei". Como ela expóe o fato da igualdade irrealizada, ao mesmo tempo, ela também introduz e fornece o necessário refúgio de igualdade. De maneiras empiricamente corporificadas, o processo da autoridade contrapontística realiza as verdades confirmadas sobre uma igualdade disponível e acessível a todo indivíduo. 
Revista de Antropologia, São Paulo, USP, 2006, v. 49 no 1.

Torres de relógio e semáforos - construídos e instalados durante o domínio britânico para instilar ordem e obediência mensuradas entre os colonizados - erguem-se como monumentos a uma hegemonia contraditória. Hoje, nenhum desses relógios badala ou marca seu regime de pontualidade sobre a Guiana litorânea. Nesses edifícios, a hora do meridiano de Greenwich não pode mais ser reproduzida e retransmitir o comando da minúscula colina em Londres para a imensa costa da América do Sul. Mesmo quando o consumismo capitalista e o sentimento desenvolvido do individualismo autônomo cultivaram mercados para a compra de "pedaços-de-tempo" pessoais (relógios), estes se tornaram adereços cênicos no drama do status, em vez de instrumentos de docilidade para os guianenses contrapontísticos. De maneira análoga, as ruas de Georgetown têm semáforos mais como lembretes do fracasso da nação em se tornar moderna ou de seu sucesso em derrotar o regime $\mathrm{da}$ ideologia colonial. As subjetividades individuais confiantes de seus usuários cuidadosamente negociam cruzamentos movimentados, evitando o tipo de dano que presumivelmente resultaria da ausência de uma autoridade desaparecida. Encontrado não apenas nesses locais específicos, mas também em toda a sociedade guianense, o contraponto das visibilidades lateral e axial representa a autoridade contrapontística de uma resposta bem característica à existência no mundo moderno. É o tipo de resposta que os soldados baseados em Kanashen levavam com eles para a floresta.

No tempo das matanças de Jonestown, os soldados fizeram sua experiência, vivida e guardada na memória, de identidade contrapontística ressoar pela floresta. Eles intencionalmente descarregaram a solidão e o tédio da vida cotidiana na floresta, com o doce alarido de suas vozes. O barulho que faziam todo dia podia ser ouvido a quilômetros de distância, ribombando na muralha de árvores e ricocheteando de volta para eles no quartel. Os soldados encontraram refúgio da necromancia da 
solidão impondo uma presença intrusiva à volta deles. Ao fazer isso, arrastaram seus camaradas para o mundo compartilhado de serem invadidos e terem de retaliar do mesmo modo. Esses jovens já sabiam como se armar contra a experiência cívica da solidão moderna e, na floresta, intuitivamente lançaram mão dessas táticas. Eles trouxeram consigo da sociedade litorânea o conhecimento aprendido da autoridade contrapontística. Quando as notícias de Jonestown chegaram até eles por rádio de unidades do exército próximas à cena, a incredulidade, como a de outros guianenses do litoral, estava impressa em seus rostos e penetrava as várias tentativas de explicar o fato. Como os Waiwai, os soldados não podiam sondar os impulsos dos templários ao retirar a própria vida e a de seus assemelhados em tais circunstâncias. Como os Waiwai, os soldados já possuíam e utilizavam meios sociais viáveis de erradicar a solidão individual, mas esse meio se mostrou inadequado para interpretar as ações dos templários do ponto de vista dos templários.

\section{Estética celular}

Eu não quero me aprofundar no que ocorreu em Jonestown. Muito já se escreveu sobre a morte de 922 cidadãos norte-americanos na região noroeste da Guiana em 18 de novembro de 1978 (Chidester, 1988; Hall, 1987; Lewis, 1979; Maaga, 1998; Mills, 1979; Weightman, 1983). Aqui, meu principal interesse reside nos limites do conhecimento que informaram as ações que ocorreram naquele exato dia. Busco uma antropologia do fato que revele algo da qualidade das relaçóes existentes entre a sociedade e seus membros, particularmente se inseridas em um conjunto de análises comparativas. Assim, quando posicionado para observar a sociedade nacional dos Estados Unidos não de uma perspectiva do fetichismo econômico ou do delírio religioso, mas a partir do 
Revista de Antropologia, São Paulo, USP, 2006, v. 49 no 1.

que eu chamo de estética da existência celular, as mortes em Jonestown não se mostram extraordinárias, mas um resultado previsível da vida na mais avançada, talvez, das sociedades industrializadas.

Eu não irei pôr a nu as teorias da alienação capitalista, geralmente citadas como a causa do agudo desenvolvimento do individualismo moderno (Lewis, 1979). Acredito que elas sejam suspeitas, pois quase sempre subentendem uma alternativa socialista e, portanto, não expõem criticamente o problema do poder estatal centralizado. Eu não acho que o arqui-rival político do capitalismo seja o comunismo, ele é antes um co-sócio estrategicamente situado em oposição a seu oponente para desviar a atenção do fato de que ambos surgiram historicamente do mesmo imaginário e da mesma formação social modernos. A melhor situação para testemunhar essa afirmativa talvez seja a acomodação entre ideologia política e religiosa da Igreja do Povo do Templo, em que o socialismo apostólico era a principal teologia de seus fiéis.

Também não me deixarei seduzir por teorias sociopsicológicas, pretensas ou genuínas, como as da "lavagem cerebral" e da "dissonância cognitiva” para explicar o redobrado sentimento de angústia e solidão que geralmente se alega ser indicativo da vida ocidental moderna. Para mim, essas teorias parecem predominar porque, no interior dos paradigmas culturais que as produzem, o espaço para a identidade e a motivação já está ocupado por um forte sentimento do ego independente. Nesse espaço, o cérebro e a cogniçãa são considerados os atores principais da ação humana. Portanto, cérebros fracos e a resposta cognitiva infantil (em vez das realidades da existência social) explicam o final drástico dessa gente solitária influenciada pelo arrebatamento de líderes de cultos carismáticos, cantores famosos de heavy metal e do próprio Diabo. Em vez disso, minha hipótese será a de supor que o conhecimento cultural sobre a individualidade, reunida em sociedade, revela bastante sobre os significados das ações de seus membros e sobre as formas por elas assumidas. 
Mentore, G. O triunfo e a dor da beleza...

Se alguém quisesse, poderia traçar com muita facilidade a ansiedade que o Estado moderno revela sobre seu direito legítimo de usar a violência para sustentar firmemente seu ponto de vista sobre a individualidade. Nós podemos constatar, por exemplo, a marca da preocupação do Estado em seu próprio poder de matar por meio de alguns de seus evocativos rituais, crenças e expressóes extáticas do século XX, como o deslocamento de exércitos em guerras internacionais, as "limpezas" raciais do Holocausto sancionadas pelo governo e a pena capital. $\mathrm{O}$ nervosismo se origina em parte, creio, das tremendas responsabilidades que o Estado tomou para si ao ser o único a deter o uso legítimo da violência. $\mathrm{O}$ que vale para sistemas econômicos e para o trabalho aplica-se às sociedades humanas politicamente organizadas e à violência: a sociedade parece reconhecer, de vários modos, que cada um e todos os seus membros têm o potencial de utilizar a força física. Alguém poderia dizer que canalizar essa força para a produção econômica e para o poder político tende a ser o interesse fundamental de todas as sociedades. Como parte de nosso contato social com o Estado e como um testemunho de nosso isolamento vulnerável, nós, cidadãos modernos, concordamos em sacrificar ao Estado o nosso sabido potencial de utilizarmos individualmente a força. Em outras palavras, idealmente, o Estado utiliza a violência de modo legítimo em nosso nome.

As maneiras notáveis de administrar a energia humana de seus cidadãos, elaboradas pelas sociedades modernas ocidentais, indicam consistentemente para teorias de racionalização da eficiência lógica. $\mathrm{O}$ que parece informar essas teorias em ter em mira a energia corporificada dos indivíduos é um conhecimento sobre o eu consistentemente propagado. Assim, primeiro ao objetivar a subjetividade individual como autônoma, dirigindo-se diretamente a essa autonomia, satisfazendo-a com desejos independentes, atribuindo-lhe laços jurídicos dominantes e, em conseqüência, construindo suas células de identidade isoladas, o Estado 
Revista de Antropologia, São Paulo, USP, 2006, v. 49 no 1.

moderno se oferece taticamente como o protetor confiante, merecedor da lealdade de seus súditos autônomos. Essa confiança, no entanto, desmente uma ansiedade, por algum tempo ela permanece como pretensão de conhecer o assunto - esse conhecimento só pode ocorrer quando primeiro se aceita uma carência epistemológica e um obstáculo ao conhecimento do assunto.

Inserir os direitos humanos dos indivíduos na lei, encorajar debates sobre tais direitos e situar o princípio da lei em conceitos constantemente deliberados sobre a vida humana, tudo isso contribuiu para uma usurpação. Eu me refiro à usurpação da autoridade legítima, que domina o indivíduo por meio de categorias tão tradicionais como família, lar, vizinhança, aldeias, clãs e supostas tribos. Nas sociedades políticas modernas, a nação se tornou a comunidade ideal; por ela, os mais fortes e abrangentes sentimentos de devoção, presumivelmente, deveriam fluir. Em outras palavras, a comunidade nacional pretende ser a forma cultural das relações dominantes, na qual o Estado e seus cidadãos deveriam procurar e exercer mutuamente as lealdades primárias.

A obediência ao Estado e seu poder de exigir tal obediência por meio de sentimentos de lealdade e devoção pela nação dependem, primeiro, de isolar cada cidadão em sua identidade celular. Em nosso mundo moderno, essas identidades regularmente aparecem como raça, classe, gênero e idade. Elas se tornaram os caminhos que conduzem a um tipo moderno de individualismo, no qual todos nós deveríamos estar engajados, construindo, monitorando e policiando não apenas para o nosso próprio sentido de eu, mas também para o tipo de conhecimento que o Estado tem dele mesmo por meio de seus membros, os cidadãos. Corpos marcados por raça, classe, gênero e idade auxiliam (ao menos temporariamente) a mitigar qualquer ansiedade que o Estado pode ter quanto ao tipo de conhecimento que ele possui sobre o que se passa no interior de cada indivíduo motivado para o potencial de utilizar a violência. 
Mentore, G. O triunfo E a dor da Beleza...

O conhecimento sobre o uso potencial da violência de corpos raciais, bem como daqueles marcados por classe, gênero ou idade, informa melhor o poder axial em sua tarefa de administrar e ordenar a sociedade de maneira mais efetiva. Além disso, cada indivíduo que invista internamente em sua própria identidade individual e crie uma realidade primordial para a diferença, fornece ao poder estatal centralizado a justificativa para a existência deste. Sempre que houver disputas entre as diferenças, o Estado pode intervir e reivindicar (geralmente por meio da lei) ser a única fonte legal ou imparcial de arbitragem.

Nós, no Estado moderno, vivemos todos os dia as contradições implícitas nas constantes proclamações sobre a disponibilidade de prazer e liberdade. Elas respingam nas paredes de nossa cela. Por exemplo, pouquíssimas crianças indo de casa para a escola em ônibus munidos de câmaras de segurança podem deixar de perceber a mácula da liberdade. Os cartazes nas salas de aula exibem antinomias em relação ao prazer: advertem todos os alunos contra o estímulo de seus corpos com drogas, álcool e sexo. Para cada estudante que tem de deixar o conforto lateral da família e do lar pelos quatro anos de vida liminar, o impacto de ser disciplinado pela academia estranhamente ecoa aquilo que sentiam em seu ninho natal. Mesmo estrear no novo status, aparentemente libertador, de "motorista habilitado" requer que se obedeça a rígidos códigos de conduta nas estradas: parar na luz vermelha, prosseguir à luz verde, ficar do lado direito da pista. Veículos feitos para viajar à velocidade de 220 quilômetros por hora não podem de modo algum ser conduzidos a essa velocidade sem infringir a lei. Em todas as direções da vida moderna nos Estados Unidos, as técnicas de comando e obediência continuam insistentemente a gerar a experiência, bem como a realizar o poder axial do Estado e a autonomia disciplinada do eu.

$\mathrm{O}$ que tudo isso pode significar para a compreensão das mortes em Jonestown e para todos os outros famosos assassinatos em massa come- 
Revista de Antropologia, São Paulo, USP, 2006, v. 49 no 1.

tidos por cidadãos norte-americanos durante o final do século XX? Eu diria inicialmente que a resposta gira em torno de tentativas de reapropriação da violência como uma expressão do fortalecimento individual e do aniquilamento da solidão. Na cultura popular, nós regularmente suspendemos nosso sentido da realidade quando somos bombardeados por imagens cruas de violência nas telas. A natureza viciosa da violência e seu poder de ferir e matar todos tornam-se seguros nas telas de cinema. E, mesmo para aqueles de nós que nunca experimentamos a realidade visceral de arrancar a vida ou provocar a morte (e, de fato, note que nem sequer temos de matar uma galinha para comermos), nós devemos perder de vista o conhecimento e a verdade de que a violência física pode ferir e matar. Enquanto os cidadãos comuns devem desistir do direito de utilizar a violência e o Estado (caso aspire a ser moderno ao estilo ocidental) deve usar esse direito em nome de seus cidadãos, ambos, no entanto, também devem reter a confiança no poder da violência de produzir seus efeitos devastadores. Em um mundo desses, poder e violência têm de estar entrelaçados, constituir uma unidade e assim permanecer. Assim, conforme essa lógica, a reapropriação da violência pelos templários deve ser vista como uma reapropriação do poder.

Ao aceitar a autonomia mas não o isolamento da existência celular, $o$ individualismo moderno parece ter atingido algo mais humanamente íntimo do que a força jurídica preventiva do Estado. Ele busca a comunidade lateral: mais perto e ao mesmo tempo mais intuitiva do que a fraternidade imaginada da nação e o laço filial do Estado. Quando isso não pode ser encontrado ou, quando achado, não pode preencher a condição de erradicar a profunda solidão do ser celular ou não pode defendêlo contra ataques, medidas drásticas que se materializam com freqüência. Quanto a isso, a identificação particular desse individualismo com o poder e com os procedimentos deste, utilizando-o para afirmar o caráter distintivo de um individualismo celular autônomo acuado, tornou a 
Mentore, G. O triunfo e a dor da beleza...

violência de Jonestown bastante alinhada com a cultura e a sociedade norte-americanas.

Os templários, em seu estilo de reapropriação, o próprio rito do suicídio fora praticado muitas vezes antes deles, sempre demonstraram um certo tipo de autofortalecimento. O que é irônico, pois, por um lado, seus atos de auto-imolação podem ser vistos como o produto de seguidores extremamente obedientes, seguidores sem nenhum meio disponível para alcançar a liberdade por meio de uma vontade de poder. Mesmo se considerássemos suas crenças e ações à mesma luz que geralmente dirigimos a nacionais devotados e patrióticos, que prontamente são voluntários, para morrer e lutar por sua nação nas forças armadas, a ironia pode não parecer estranha.

Os templários descobriram em sua igreja e seu pastor uma proximidade de conforto humano, assim como devoção a uma causa que lhes assegurasse um instante de fértil realização da individualidade. É importante ter em mente que, em Jonestown, $70 \%$ a $80 \%$ dos templários se consideravam afro-americanos urbanos. Também se deve levar em conta que, de todos os moradores de Jonestown, dois terços eram mulheres: $49 \%$ mulheres negras, 14\% tinham 66 anos ou mais. Somente $10 \%$ de todos os moradores eram homens brancos. As 70 crianças pequenas, com 5 anos ou menos, somavam $8 \%$, e as crianças maiores e os jovens, entre 6 e 19 anos, 417 ao todo, somavam 46\% da população total (Maaga, 1998, p. 9). Do rigor de disciplinas técnicas que já estavam disponíveis como parte de seu conhecimento cultural, esses homens, mulheres e crianças imaginaram e viveram um paraíso na Terra dentro da comunidade.

Concretizada tanto por formas axiais e laterais de relações comunais, no entanto, foi a estética celular das últimas, com seu rígido arcabouço hierárquico, que imprimiu as características mais evidentes da comunidade. Guardas armados durante os rituais de adoração, torres de vigia 
em torno do lugar, rotinas organizadas de trabalho, educação, sono e banhos, bem como devoção completa e irrestrita ao pastor, tudo para o funcionamento adequado e para a domínio do poder axial. No final, a questão para os templários não era a autodestruição: nas palavras do pastor e "pai" Jim Jones, "Nós não cometemos suicídio, cometemos um ato de suicídio revolucionário" (id., p. 164). Eles deram suas vidas como uma oferenda de morte para proteger sua igreja e o que ela significava para eles. Na época, ambos estavam sitiados por agentes do Estado e pela opinião pública dos Estados Unidos. Eles sacrificaram as próprias vidas e a de suas crianças como uma oferenda para Jones e para Deus e, ao fazerem isso, reclamaram sua vontade de poder e também o produto da violência desse poder.

\section{Conclusão}

A simples hipótese desenvolvida neste artigo foi, quanto aos Waiwai, a de que o privilégio da visibilidade lateral sugere idéias a respeito de um indivíduo fractal associado ao poder recursivo, enquanto, para as sociedades dos Estados Unidos e do litoral da Guiana, o privilégio da visibilidade axial sugere conceitos sobre um indivíduo autônomo associado a relações de poder celular e contrapontística, respectivamente. Foi afirmado que, com a preocupação de atingir maior eficiência no funcionamento de suas relações políticas com os cidadãos, o desejo do Estado moderno, expresso por meio do uso privilegiado da visibilidade axial, atenua as relaçóes laterais e produz formas de indivíduos solitários e categoricamente isolados.

Para a sociedade litorânea da Guiana, tendo de viver constantemente no interior de uma ética da modernidade, o cenário é o de uma negação de sucumbir a tais noções de identidade. Para ela, o resultado aparente 
Mentore, G. O triunfo E a dor da Beleza...

tem sido um sentimento coletivo de insatisfação quanto à realização da modernidade: em outras palavras, uma contínua experiência de sentirse "Terceiro Mundo". Em primeiro lugar, porque a visibilidade lateral ainda permanece uma fonte importante para o uso expressivo da autoridade contrapontística, os efeitos debilitantes de ser Terceiro Mundo não produziram, contudo, uma sociedade desmoralizada. Para os templários, que se encontravam na Guiana com os valores dos Estados Unidos, suas tentativas de erradicar a experiência cívica da solidão moderna levou-os ao "culto", ao conforto da congregação e, em última instância, à serena bem-aventurança da vida após a morte.

Permitam-me concluir com essa nota um tanto hesitante, mas sugestiva, extraída do material waiwai e situada no contexto mais amplo dos modos de conhecimento ameríndios. Um dos palpites velados que sustento há algum tempo - com freqüência guiando subliminarmente minha pesquisa - é a suspeita de que os modos de conhecimento ameríndios possuem a habilidade de manter um controle firme de múltiplos conceitos no exato momento em que são utilizados. Em contraste, os estilos lineares de conhecimento ocidentais, sujeitos à história particular da metafísica, força-nos a deixar escapar, no momento em que mais precisamos utilizá-las, as estruturas nas quais os conceitos são produzidos. Portanto, representar o conhecimento ameríndio se torna uma tarefa um tanto difícil para o antropólogo quando os meios de representação não podem preencher o abismo entre o signo e o significante, exceto, claro, pela antinomia da suspensão do próprio conhecimento. Os modos ameríndios de conhecer, eu creio, não têm o desejo de se restringir ao princípio de verdade, pois a verdade já é: a verdade já é vivida e não, como ocorre com tanta freqüência conosco, desejada, erguendo-se diante de nós para que ainda seja possuída. Talvez, então, a delicada cirurgia que venho tentando realizar tenha sido feita pela professora antes de mim e, antes dela, pelos ensinamentos de uma experiência ameríndia. 


\section{Notas}

1 Escrevi a base das idéias deste ensaio para a conferência "No mundo e sobre o mundo: modos de conhecimento ameríndios", organizada por mim e Fernando Santos-Granero, que ocorreu na Universidade da Virgínia, no campus de Charlottesville, em 28 e 29 de novembro de 2005. Sou grato a todos os participantes dessa conferência por seus comentários úteis e pelo apoio generoso. Sou particularmente grato a Laura Mentore, aos Waiwai e Wapishana da aldeia Erepoimo por suas contribuições substantivas as minhas idéias. Dedico este ensaio a Ėana e Kamina.

2 Quanto a isso, retomo não apenas Michel Foucault (1978, p. 200), mas também muitos antropólogos que antes dele escreveram sobre o tema do espaço social.

3 Ver Rosengren, Santos-Granero e Werlang, neste número, para uma discussão de noçôes similares entre outros povos ameríndios.

4 Ver Passes, neste número, para a importância similar da metáfora na matemática pa'ikwené.

5 Eu creio que é a uma questão de um certo tipo de consciência que Edouard Glissant (1989, pp. 195-220) se refere como a promessa de um "teatro nacional" reflexivo que vive nas crenças folclóricas antilhanas, inconsciente de seu poder de mudança positivo.

\section{Bibliografia}

ABRAHAMS, Roger D.

1983 The Man-of-Words in the West Indies: Performance and the Emergence of Creole Culture, Baltimore, Johns Hopkins University Press.

CHIDESTER, David

1988 Salvation and Suicide: An Interpretation of Jim Jones, the Peoples Temple, and Jonestown, Bloomington, Indiana University Press.

FOUCAULT, Michel

1978 Discipline and Punish: The Birth of the Prison, New York, Vintage Books. 
Mentore, G. O triunfo E a dor da Beleza...

GLISSANT, Edouard

1989 Caribbean Discourse: Selected Essays, Charlottesville, University of Virginia Press.

HALL, John R.

1987 Gone from the Promised Land: Jonestown in American Cultural History, New Brunswick, N.J., Transaction Publishers.

LEWIS, Gordon K.

1979 Gather with the Saints at the River: The Jonestown Guyana Holocaust 1978, Río Piedras, University of Puerto Rico, Institute of Caribbean Studies.

MAAGA, Mary McCormick

1998 Hearing the Voices of Jonestown, New York, Syracuse University Press.

MILLS, Jeannie

Six Years with God, New York, A. and W.

OVERING, Joanna (ed.)

1985 Reason and Morality, London \& New York, Tavistock Publications.

OVERING, Joanna \& PASSES, Alan (ed.)

1999 The Anthropology of Love and Anger: The Aesthetics of Conviviality in Native Amazonia, London/New York, Routledge.

PATTERSON, Orlando

1982 Slavery and Social Death: A Comparative Study, Cambridge, MA, Harvard University Press.

RIESMAN, Karl

1974 "Contrapuntal Conversations in an Antiguan Village", in BAUMAN, R. \& SHERZER, J. (ed.), Explorations in the Ethnography of Speaking, Cambridge, Cambridge University Press.

RODNEY, Walter

1981 A History of the Guyanese Working People, 1881-1905, Baltimore, Johns Hopkins University Press. 
Revista de Antropologia, São Paulo, USP, 2006, v. 49 no 1.

SANDERS, Andrew

1987

Powerless People: An Analysis of the Amerindians of the Corentyne River, London, Macmillan Publishers.

TAUSSIG, Michael

1993

Mimesis and Alterity: A Particular History of the Senses, New York, Routledge.

WAGNER, Roy

1991

"The Fractal Person", in GODELIER, M. \& STRATHERN, M. (ed.), Big Men

and Great Men, Cambridge, Cambridge University Press, pp. 123-35.

WEIGHTMAN, Judith Mary

1983

"Making Sense of the Jonestown Suicides: A Sociological History of Peoples Temple", Studies in Religion and Society, vol. 7, Lewiston, NY, Edwin Mellen Press.

WILSON, Peter J.

1973

Crab Antics: The Social Anthropology of English-speaking Negro Societies of the Caribbean, New Haven, Yale University Press.

ABSTRACT: The principal assumption put forward in this paper will be that for the Waiwai the privileging of lateral visibility brings ideas about a fractal individual into association with recursive power, while for coastal Guyanese and U.S. societies, respectively, the privileging of axial visibility brings concepts about an autonomous individual into association with contrapuntal and cellular relations of power. It will be argued that, contrary to the Waiwai situation, in its agenda to achieve a greater efficiency for the workings of its political relations with its citizens, the desire of the modern state, expressed through its privileged use of axial visibility, de-emphasizes lateral relations and brings about categorically isolated and solitary forms of individuals.

KEY-WORDS: fractality, visibility, individuality, knowledge, truth, power.

Tradução de André Pinto Pacheco.

Aceito em novembro de 2005. 